\title{
CONFERENCIA
}

\section{TRASTORNOS DEL SUEÑO: Un Abordaje Miofuncional y Relaciones Estructurales Orofaciales}

\author{
Esther Bianchini ${ }^{4}$
}

El síndrome de apnea obstructiva del sueño - SAOS es causada por condiciones multifactoriales, con gran incidencia en la población general. La etiología y factores de risco más importantes, que originan el SAOS y el ronquido, se refieren a: obesidades y otras comorbilidades; problemas respiratorios obstructivos y/o centrales, así como los problemas estructurales maxilo-mandibulares y las alteraciones de los tejidos blandos. Esos últimos, de especial interese a los logopedas.

Las condiciones de los músculos orofaríngeos son decisivas para la génesis de la SAOS yel ronquido. Así, la evaluación miofuncional orofacial y la verificación de los exámenes complementares específicos para SAOS y Ronquido se constituyen en los ítems esenciales para el diagnostico y planeamiento terapéutico fonoaudiológicos.

La desproporción maxilo-mandibular, en especial la deficiencia mandibular, es una de las más limitantes relaciones estructurales para el suceso de la terapia, muchas veces necesitando de cirugía ortognática previa, seguida de la abordaje fonoaudiológica miofuncional orofacial. Esa terapéutica deberá englobar los procedimientos específicos para rehabilitación de la cirugía ortognática, donde se busca la flexibilidad de la musculatura supra-hioidea que se ha estirado en el procedimiento quirúrgico, más la tonificación y apertura de la orofaringe.

Cuando se indica la Terapia Miofuncional orofacial para SAOS y ronquido, la énfasis del tratamiento deberá ser en los músculos supra-hioideos, músculos extrínsecos de la lengua priorizando tonificación de los depresores de la lengua; así como músculos del paladar blando y de la úvula. La respiración y correcta utilización del músculos de los labios y de las mejillas igualmente deberán ser tonificados.

Después de la finalización de los procedimientos terapéuticos específicos, es necesaria la manutención de la musculatura con algunos pocos ejercicios para mantener los resultados obtenidos.

4. Fonoaudióloga; Especialista en Motricidad Orofacial; Maestría en Disturbios de la ComunicaciónPontifícia Universidad Católica de São Paulo - PUC-SP; Doctora en Ciencias - Fisiopatología Experimental Programa de Posgrado. Facultad de Medicina - Universidad de São Paulo - FMUSP; Presidente Del Departamento de Fonoaudiologia da Asociación Brasileira del Sueno - ABSono - Brasil; Profesora en CEFAC - Posgrado en Salud y Educación; Profesora de la Pontificia Universidad Católica de São Paulo Programa de Posgrado - Maestría y Doctorado en Fonoaudiologia ; Directora de la Clínica de Logopedia: E.Bianchini Fonoaudiologia - São Paulo. 